\title{
Measuring the Subjective Well-Being of Diverse Populations in the U.S.
}

\author{
Lisbeth Nielsen ${ }^{1}$
}

Published online: 28 March 2017

(C) Springer Science+Business Media Dordrecht and The International Society for Quality-of-Life Studies (ISQOLS) (outside the USA) 2017

Since 1997, the National Institute on Aging (NIA)'s Resource Centers for Minority Aging Research (RCMAR) have sought to diversify the aging research workforce and promote quality research on minority aging populations. RCMAR goals include improving measurement of the health and well-being of underrepresented and disadvantaged populations and strengthening the design of interventions targeted at reducing health inequities between racial and ethnic groups, particularly those that manifest at older ages. During a RCMAR-sponsored preconference at the 2015 Annual Meeting of the Gerontological Society of America ("Subjective Well-Being Assessment in Minority Aging Research"), participants reviewed advances in the measurement of subjective well-being and applications in health disparities research. The papers in this special section reflect initial efforts by RCMAR-affiliated investigators to tackle issues raised during the workshop.

Weech-Maldonado et al. (2017) studied 221 adults recruited from 39 primary care practices in Alabama and found that adequate health literacy and better perceived health were associated with an increase in the likelihood of happiness. Moreover, those with sufficient income were more likely to have better perceived health, and were more likely to be happy. Teresi et al. (2017) evaluated the Feeling Tone Questionnaire (FTQ) in a sample that included 4960 non-Hispanic White, 1144 non-Hispanic Black, and 517 Hispanic community and institutional residents receiving long-term supportive services. They found that negatively worded items had relatively low reliability; 9-item and 13-item positive affect scales had high reliability and little differential item functioning (i.e., items performed equivalently) for race/ethnic subgroups. Palimaru and Hays (2017) investigated associations between a quality of life item and HRQOL items in two datasets ( $n=21,133$ and $n=2996)$ collected as part of the U.S. Patient Reported Outcomes Measurement Information System (PROMIS®) project. They

Lisbeth Nielsen

lisbeth.nielsen@nih.gov

1 National Institute on Aging, Bethesda, MD, USA 
found that health-related quality of life measures accounted for $69 \%$ to $75 \%$ of variance in perceptions of overall quality of life.

The NIA increased its support for research on subjective well-being during the last decade to broaden our understanding of individuals' experience of the aging process. Subjective well-being measures include self-reports of momentary daily experiences of suffering and positive emotions, as well as perceptions of overall life satisfaction or dissatisfaction and of life purpose and meaning. Subjective well-being measures extend the concept of health beyond the mere presence or absence of illness or disability to incorporate the notion of positive health and functioning, which has received limited attention in the health sciences. But these measures have not been included regularly in epidemiological studies or clinical trials, thus limiting our ability to identify potential intervention targets, or to assess the extent to which our behavioral and biomedical interventions improve the quality of life of older adults.

Advances in subjective well-being research have been bolstered by international efforts to improve metrics by which societal progress is assessed. In line with these efforts, NIA has supported the development of new measures and the collection of publicly-available population level data on subjective well-being. These data may serve as a critical index of the success or failure of interventions and policies aimed at improving the health of older people, complementing other health measures and economic indicators. NIA-supported projects contributing to this endeavor include the Roybal Center for Translational Research on Aging at the Center for Health and Well-being at Princeton University (https://chw.princeton.edu/researchprograms/center-translational-research-aging), and numerous NIA-supported life course longitudinal surveys, including the Health and Retirement Study (HRS: http://hrsonline.isr.umich.edu/), Midlife in the United States (MIDUS: http://midus. wisc.edu/), the English Longitudinal Study of Aging (ELSA: http://www.ifs.org. uk/elsa/), the Survey on Health and Retirement in Europe (SHARE: http://www. share-project.org/); the Rush Memory and Aging Project (http://www.rush. edu/rumc/page-R12392.html), and the Panel Study of Income Dynamics (PSID: http://psidonline.isr.umich.edu/default.aspx). NIA has also funded a well-being module on the American Time Use Survey at the Bureau of Labor Statistics (ATUS: http://www.bls.gov/tus/wbmquestionnaire.pdf). Using data from these and other studies, NIA-supported researchers have documented a U-shaped age profile of wellbeing in the US population (Stone et al. 2010), a positive association between daily experiences of positive affect and longevity (Steptoe and Wardle 2011), and associations between higher levels of purpose in life and reduced risk of mortality (Boyle et al. 2009), Alzheimer's disease (Boyle, Buchman, Barnes, \& Bennett, 2010), and disability (Boyle, Buchman, \& Bennett, 2010), after taking background health and demographic factors into account. The MIDUS study was designed to allow researchers to examine the links between biomarkers of health and dimensions of well-being - particularly its eudaimonic aspects - with emerging findings showing links between subjective wellbeing and emotional recovery to a negative stimulus in the laboratory (Schaefer et al. 2013), metabolic syndrome (Boylan and Ryff 2015), cognitive function (Lewis et al. 2016), and mortality (Tsenkova et al. 2007). Harmonized well-being measures in the HRS and ELSA allowed researchers to examine cross-national differences in the links between educational attainment and subjective well-being in later life (Jivraj and Nazroo 2014). Finally, the link between subjective well-being and income both at the 
individual (Kahneman et al. 2006) and national level (Kahneman and Deaton 2010) has been explored by researchers at the NIA-funded Roybal Center, using data from a variety of surveys including the ATUS and the Gallup World Poll.

In support of ongoing efforts to improve the quality of available population-level data on subjective well-being, the National Institute on Aging sponsored the development of a report on Guidelines on Measuring Subjective Wellbeing by the Organization for Economic Co-operation and Development (through the Committee on National Statistics at the National Academy of Sciences; Organization for Economic Cooperation and Development 2013). And in 2012, the NIA, in collaboration with the UK Economic and Social Research Council, sponsored a U.S. National Academy of Sciences Panel on Measuring Subjective Well-Being in a Policy-Relevant Framework (jointly sponsored by the Committee on National Statistics and the Board on Behavioral, Cognitive, and Sensory Sciences), which offered advice on the collection of data on subjective well-being by national statistical agencies and in health-related research studies around the world (National Research Council 2013). The panel evaluated methods for studying experienced well-being (reports of momentary positive and rewarding, or negative and distressing, states), offered guidance on what research would be needed for such measures to be useful for tracking changes in well-being in the population relevant for policymaking, and considered whether such measures might, at some future date, be treated as outputs of a policy-relevant satellite account that would be adjunct to the Gross National Product.

The National Academy of Sciences Panel concluded that currently the most useful application of these measures will be for targeted policy questions affecting specific sub-populations, rather than for global monitoring purposes. Thus, the extension of subjective well-being research to the study of health disparities and to characterizing the experiences of under-represented or disadvantaged populations in our society is both important and timely. The RCMAR GSA preconference on Subjective Well-being Assessment in Minority Aging Research and the papers in this special section represent a useful first step in that direction.

\section{References}

Boylan, J. M., \& Ryff, C. D. (2015). Psychological well-being and metabolic syndrome: Findings from the midlife in the United States national sample. Psychosomatic Medicine, 77(5), 548-558.

Boyle, P. A., Barnes, L. L., Buchman, A. S., \& Bennett, D. A. (2009). Purpose in life is associated with mortality among community-dwelling older persons. Psychosomatic Medicine, 71(5), 574-579.

Boyle, P. A., Buchman, A. S., Barnes, L. L., \& Bennett, D. A. (2010a). Effect of a purpose in life on risk of incident Alzheimer disease and mild cognitive impairment in community-dwelling older persons. Archives of General Psychiatry, 67(3), 304-310.

Boyle, P. A., Buchman, A. S., \& Bennett, D. A. (2010b). Purpose in life is associated with a reduced risk of incident disability among community-dwelling older persons. The American Journal of Geriatric Psychiatry, 18(12), 1093-1102.

Jivraj, S., \& Nazroo, J. (2014). Determinants of socioeconomic inequalities in subjective well-being in later life: A cross-country comparison in England and the USA. Quality of Life Research, 23(9), 2545-2558.

Kahneman, D., \& Deaton, A. (2010). High income improves evaluation of life but not emotional well-being. Proceedings of the National Academy of Sciences of the United States of America, 107(38), 1648916493.

Kahneman, D., Krueger, A. B., Schkade, D., Schwarz, N., \& Stone, A. A. (2006). Would you be happier if you were richer? A focusing illusion. Science, 312(5782), 1908-1910. 
Lewis, N. A., Turiano, N. A., Payne, B. R., \& Hill, P. L. (2016). Purpose in life and cognitive functioning in adulthood. Neuropsychology, Development, and Cognition. Section B, Aging, Neuropsychology and Cognition, 1-10.

National Research Council. (2013). Subjective well-being: Measuring happiness, suffering, and other dimensions of experience. Panel on measuring subjective well-being in a policy-relevant framework. In A. A. Stone \& C. Mackie (Eds.), Committee on National Statistics, Division of Behavioral and Social Sciences and Education. Washington, DC: The National Academies Press.

OECD (2013). OECD guidelines on measuring subjective well-being. Paris: OECD Publishing. DOI:10.1787 /9789264191655-en

Palimaru, A., \& Hays, R. D. (2017). Associations of Health-Related Quality of Life with Overall Quality of Life in the Patient Reported Outcomes Measurement Information System (PROMIS®) Project. Applied Research in Quality of Life, $X(\mathrm{X}), \mathrm{xx}-\mathrm{xx}$.

Schaefer, S. M., Boylan, J. M., van Reekum, C. M., Lapate, R. C., Norris, C. J., Ryff, C. D., \& Davidson, R. J. (2013). Purpose in life predicts better emotional recovery from negative stimuli. PloS One, 8(11), e80329. doi:10.1371/journal.pone.0080329.

Steptoe, A., \& Wardle, J. (2011). Positive affect measured using ecological momentary assessment and survival in older men and women. Proceedings of the National Academy of Sciences of the United States of America, 108(45), 18244-18248.

Stone, A. A., Schwartz, J. E., Broderick, J. E., \& Deaton, A. (2010). A snapshot of the age distribution of psychological well-being in the United States. Proceedings of the National Academy of Sciences of the United States of America, 107(22), 9985-9990.

Teresi, J. A., Ocepek-Welikson, K., Toner, J. A., Kleinman, M., Ramirez, M., Eimicke, J. P., Gurland, B. J., \& Siu, A. (2017). Methodological issues in measuring subjective well-being and quality-of-life: Applications to assessment of affect in older, chronically and cognitively impaired, ethnically diverse groups using the Feeling Tone Questionnaire. Applied Research in Quality of Life, $X(\mathrm{X}), \mathrm{xx}-\mathrm{xx}$.

Tsenkova, V. K., Love, G. D., Singer, B. H., \& Ryff, C. D. (2007). Socioeconomic status and psychological well-being predict cross-time change in glycosylated hemoglobin in older women without diabetes. Psychosomatic Medicine, 69(8), 777-784.

Weech-Maldonado, R., Miller, J. M., \& Lord, J. C. (2017). The Relationships Among Socio-Demographics, Perceived Health, and Happiness. Applied Research in Quality of Life, X(X), xx-xx. 